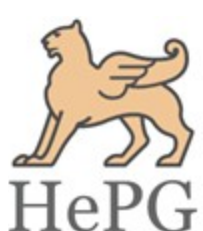

ISSN: 2348-1900

Plant Science Today

http://www.plantsciencetoday.online

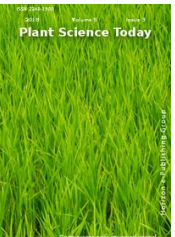

Research Article

\title{
Cellular response of oxidative stress when sub1A QTL of rice receives water deficit stress
}

\author{
Indraneel Saha ${ }^{1}$, Arnab Kumar De ${ }^{1}$, Bipul Sarkar ${ }^{1}$, Arijit Ghosh ${ }^{1}$, Narottam Dey ${ }^{2}$, and Malay \\ Kumar Adak ${ }^{*}$
}

${ }^{1}$ Department of Botany, University of Kalyani, Kalyani 741235, West Bengal, India

${ }^{2}$ Department of Biotechnology, Visva-Bharati University, Santiniketan 731235, West Bengal, India

\section{Article history \\ Received: 06 March 2018 \\ Accepted: 08 April 2018 \\ Published: 01 July 2018 \\ Copyright \\ (c) Saha et al (2018). This is an open-access article distributed under the terms of the Creative Commons Attribution License, which permits unrestricted use, distribution, and reproduction in any medium, provided the original author and source are credited.}

\section{Editor}

K K Sabu, Jawaharlal Nehru Tropical Botanic Garden and Research Institute, India

\section{Publisher}

Horizon e-Publishing Group

\section{"Correspondence}

Malay Kumar Adak

\mkadak09@gmail.com

\begin{abstract}
In this experiment, sub1A quantitative trait loci (sub1A QTL) of rice were evaluated for dehydration responses through different aspects of cellular responses. Through variations of dehydration exposure, rice seedlings recorded a significant increase in superoxide $\left(\mathrm{O}_{2} \cdot\right)$ and hydrogen peroxide $\left(\mathrm{H}_{2} \mathrm{O}_{2}\right)$, the former by 1.80 fold and the latter by 2.10 fold. Nicotinamide adenine dinucleotide phosphate oxidase activity fairly correlated with lipid peroxidation $(\mathrm{r}=$ 1.96). Both 2,2-diphenyl-1-picrylhydrazyl (DPPH) and 2,2'-azino-bis(3-ethylbenzothiazoline-6sulphonic acid) (ABTS) had similar $\mathrm{IC}_{50}$ values over the control at $\mathrm{p} \leq 0.05$. Reducing power of the extract had 1.31 fold increase. The antioxidant moieties like total phenolics and flavonoids were 1.04 and 1.23 fold upregulated under stress. On the other hand anthocyanin and glutathione (GSH) did not vary much under stress except at maximum duration of stress. Superoxide dismutase (SOD) was initially stable but maximized at 8 days by 1.30 fold increase. On the contrary, guaiacol peroxidase (GPX) was seen to be downregulated by $40.94 \%$ all through the days of stress. Catalase (CAT) activity followed a similar trend, but was not significant as compared to control.
\end{abstract}

Keywords: sub1A QTL; rice; antioxidants; water deficit stress; ROS

Abbreviations: QTL, Quantitative trait loci; $\mathbf{O}_{2}$ : , Superoxide; $\mathbf{H}_{2} \mathbf{O}_{2}$, Hydrogen peroxide; NADP(H) oxidase, Nicotinamide adenine dinucleotide phosphate-oxidase; DPPH, 2,2-diphenyl-1-picrylhydrazyl;

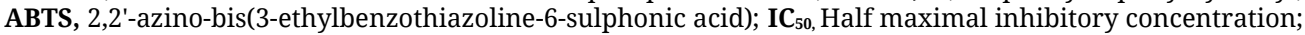
GSH, Glutathione; SOD, Superoxide dismutase; GPX, Guaiacol peroxidase; CAT, Catalase; ROS, Reactive oxygen species; RBD, Randomized block design; OD, Optical density; $\mathrm{NO}_{2}{ }_{2}$, Nitrogen dioxide; TCA, Trichloroacetic acid; KI, Potassium iodide; PVP, Polyvinyl pyrolidine; EDTA, Ethylenediaminetetra acetic acid; DTT, Dithiothreitol; BSA, Bovine serum albumin; SDS, Sodium dodecyl sulphate; $\mathbf{M n C l}_{2}$, Manganese chloride; MDA, Malondialdehyde; TBA, tert-Butyl alcohol; BHT, Butylated hydroxytoluene; $\mathbf{M g C l}_{2}$, Magnesium chloride; NBT, Nitroblue tetrazolium; PMSF, Phenyl methane sulphonyl fluoride; $\boldsymbol{\beta}$-ME, $\beta$ Mercapto ethanol; GSSG, Glutathione disulfide; LHC, Light-harvesting complex.

Citation: Saha I, De A K, Sarkar B, Ghosh A, Dey N, Adak M K. Cellular response of oxidative stress when sub1A QTL of rice receives water deficit stress. Plant Science Today 2018;5(3):84-94. https://dx.doi.org/10.14719/pst.2018.5.3.387

\section{Introduction}

In reaction to submergence stress, few rice genotypes have the unique ability to sustain under partial to complete inundation for variable periods of time. This is exhibited by a few landraces like FR13A, FR13B that show the ability to withstand hypoxic / anoxic condition and its post period effects by different mechanisms (1). In the course of developmental events, synthesis of air spaces in cortical zone of roots, accumulation of more lignin residues in the apoplastic spaces, diffusibility of oxygen through plasmodesmata and at cellular level, opening of calcium channels are the fine observations for their tolerance (2). Overexpression of few compatible solutes may resist, the 
water deficit due to poor root hydraulic conductivity of rice cultivars under submergence (3). The most determining factor in declaring a rice gentoype submergence tolerance is its capacity to handle post submergence stress. This includes oxygenic tension and intense irradiance when plants encounter when water level recedes. The oxidative burst under post submergence is the more common of the two. When water level recedes there may be an abrupt oxygenic exposure to submerged de-chlorophyllous tissues. In fact, a hastened senescence is the typical physiological response under de-submerged condition. Reactive oxygen species (ROS) cause oxidation of thiol groups and loss of tolerance (4). Rice cultivars vary with respect to submergence tolerance and their ability to prevent such induced senescence. It has been observed that sub1A QTL possessing landrace, cv. Swarna Sub1 can be sensitized with elevated redox related stress responses of inundation (5). It is an inherent character of landraces possessing sub1A QTL like elements to realize adequate growth and yield under varying depths of submergence. The rain-fed areas for rice cultivation are affected sequentially by both of flooding (specially flash flood) and soil moisture deficit / drought condition (flooding followed by dehydration in land and vice versa). Tolerance to consecutive submergence and drought stress may substantially gear up sustainability and productivity in rain-fed and low land fallows. This was clearly evident in cV. FR13A which is often affected by drought stress. FR13A is the donor of the sub1A traits to Swarna and therefore, sensitivity of cv. Swarna Sub1 to water stress needs to be explored (6). The purpose of the present experiment is to evaluate the cellular responses of the sub1A QTL in modules of osmotic stress by monitoring varying paths of antioxidation. The objective of the study was to document the response of, landraces of rice possessing the sub1A QTL, to delayed or erratic rainfall pattern.

\section{Materials and Methods}

Germination of seedlings, water stress and sample collection: The entire experiment was conducted in the experimental garden and laboratory of Plant Physiology at the Department of Botany, University of Kalyani, Kalyani $\left(22^{\circ} 58^{\prime} 30^{\prime N} 88^{\circ} 26^{\prime} 04^{\prime E}\right.$ ), West Bengal, India. Seeds of cv. Swarna Sub1 collected from Chinsurah Rice Research Station, West Bengal, were germinated under proper conditions and allowed to grow for seven days in Murashige and Skoog medium (7). Seedlings were then transferred to earthen wire pots $(20 \mathrm{~cm}$ diameter) compacted with alluvial soil ( $\mathrm{pH}$ 6.8) in 5 replications per plot in randomized block design (RBD). Plants were kept for 5 days under normal day light conditions in open air. On preliminary observation the mortality of the plants were recorded within 10 days. Thus the exposure of dehydration stress was imposed on the $2^{\text {nd }}, 4^{\text {th }}$ and $8^{\text {th }}$ days by withdrawing the irrigation. A control set was also maintained under same condition where regular irrigation was maintained. On subsequent days the plants were harvested and separated into roots and shoots and stored at $-80^{\circ} \mathrm{C}$, prior to freezing in liquid nitrogen.

Biochemical Analysis: For the biochemical analysis the followings parameters were estimated using standard protocols. Three plants from each set of replication under control and treatment were randomly chosen for testing the parameters.

Superoxide $\left(\mathrm{O}_{2 .} \cdot\right)$ content: The plant tissue was crushed with $65 \mathrm{mM}$ phosphate buffer $(\mathrm{pH}$ 7.8) under cold condition and the homogenate was collected by centrifugation at $8,000 \mathrm{xg}$ for $30 \mathrm{~min}$ at $4^{\circ} \mathrm{C}$. The assay mixture of $3 \mathrm{ml}$ solution with 65 $\mathrm{mM}$ phosphate buffer ( $\mathrm{pH} 6.8), 10 \mathrm{mM}$ hydroxylamine and $100 \mu \mathrm{l}$ supernatant was incubated at room temperature for $30 \mathrm{~min}$. To the solution, 10 $\mathrm{mM}$ sulphanilamide with $7 \mathrm{mM}$ a-napthyl amine was added and kept under dark for sufficient time. With the help of a UV/VIS spectrophotometer (Cecil, CE7200), the OD was recorded at $530 \mathrm{~nm}$ and plotted using $\mathrm{NO}_{2}{ }^{-}$as standard according to Elstner and Heupel (1976) (8).

Hydrogen peroxide $\left(\mathrm{H}_{2} \mathrm{O}_{2}\right)$ content: $\mathrm{H}_{2} \mathrm{O}_{2}$ content was determined by crushing the $500 \mathrm{mg}$ of tissue with $2 \mathrm{ml}$ of $1 \%(\mathrm{~W} / \mathrm{V})$ trichloro acetic acid (TCA) solution. The homogenate was centrifuged at $10,000 \mathrm{xg}$ for $15 \mathrm{~min}$ at $4^{\circ} \mathrm{C}$. The supernatant was treated with $10 \mathrm{mM}$ potassium phosphate buffer ( $\mathrm{pH}$ 7) and saturated solution of $1 \mathrm{mM}$ potassium iodide (KI). After 20 min of incubation in the dark, the OD was taken at $390 \mathrm{~nm}$ using $\mathrm{H}_{2} \mathrm{O}_{2}$ as standard (9).

NADP(H) oxidase activity: The sample was homogenized in $50 \mathrm{mM}$ potassium phosphate buffer ( $\mathrm{pH}$ 6.5) containing 1\% (W/V) polyvinyl pyrrolidone (PVP), $0.2 \mathrm{mM}$ EDTA, $0.1 \%$ triton, $0.1 \%$ DTT, $1 \%$ leupeptine, $5 \mathrm{mM}$ ascorbate and $0.1 \%$ BSA (bovine serum albumin). The homogenate was centrifuged at $10,000 \mathrm{xg}$ at $4^{\circ} \mathrm{C}$ for $20 \mathrm{~min}$. The supernatant was extracted with $80 \%$ ammonium sulphate precipitation followed by purification through specific buffer containing $65 \mathrm{mM}$ phosphate buffer ( $\mathrm{pH}$ 7.8), 0.1\% BSA, 0.1\% SDS. The purified material was quantified with Lowry's reagent for total protein content. The activity of $\mathrm{NADP}(\mathrm{H})$ oxidase (E.C. 1.11.1.1) was done in an assay mixture of $30 \mathrm{mM}$ sodium acetate buffer $(\mathrm{pH}$ 7.5), $0.1 \mathrm{mM}$ DTT, $0.1 \mathrm{mM}$ p-coumaric acid, 0.05 $\mathrm{mM}$ NADP(H), $5 \mathrm{mM} \mathrm{MnCl}_{2}$ and $50 \mu \mathrm{g}$ of enzyme protein. The fall in OD at $340 \mathrm{~nm}$ was recorded 
through 1 min. 1 unit (U) of enzyme activity was considered for oxidation of $\mathrm{NAD}(\mathrm{P}) \mathrm{H}$ with extinction co-efficient $\left(6.22 \mathrm{mM}^{-1} \mathrm{~cm}^{-1}\right)(10)$.

Lipid Peroxidation: Estimation of MDA content was done according to R. L. Heath and L. Packer (1968) (11). Homogenized leaf material was extracted with $10 \%$ TCA containing $0.5 \%$ TBA with centrifugation at $12,000 \mathrm{xg}, 4^{\circ} \mathrm{C}$ for $30 \mathrm{~min}$. The whole mixture was allowed to heat up to $95^{\circ} \mathrm{C}$ for $30 \mathrm{~min}$ followed by cooling on ice bath. The absorbance was read at $532 \mathrm{~nm}$ and $600 \mathrm{~nm}$ in a UV-VIS spectrophotometer. The MDA concentration was calculated by using the formula below:

$\mathrm{A}_{532}-\mathrm{A}_{600}=\varepsilon \mathrm{CL}$

Where $\varepsilon=$ Extinction co-efficient (155 is extinction co-efficient of MDA)

$$
\begin{aligned}
& \mathrm{C}=\text { Concentration } \\
& \mathrm{L}=\text { Path length (Distance of the cuvette }=1 \mathrm{~cm} \text { ) }
\end{aligned}
$$

DPPH scavenging assay: For in vitro DPPH radical scavenging assay, plant extract was incubated with $25 \mathrm{mg} / \mathrm{l}$ DPPH solution, incubated for $30 \mathrm{~min}$ at room temperature and the OD was measured at $\lambda=517 \mathrm{~nm}$ with butylated hydroxytoluene (BHT) as synthetic standard scavenger (12). The percentage of scavenging activity was calculated from the following formula:

$\%$ of scavenging $[\mathrm{DPPH}]=\left[\left(\mathrm{A}_{0}-\mathrm{A}_{1}\right) / \mathrm{A}_{0}\right] \times 100$

Where $\mathrm{A}_{0}=$ Absorbance of the blank set

$$
\mathrm{A}_{1}=\text { Absorbance of samples and standard }
$$

ABTS scavenging assay: $\mathrm{ABTS}^{+}$radical cation scavenging assay was performed on the ethanolic extract of the plant sample. $0.1 \mathrm{ml}$ of extract was reacted with $3 \mathrm{ml}$ of $\mathrm{ABTS}^{+}$solution in $2.4 \mathrm{mM}$ potassium persulphate buffer (13). BHT was used as standard and percent of scavenging activity was calculated as:

$\%$ of scavenging $[\mathrm{ABTS}]=\left[\left(\mathrm{A}_{0}-\mathrm{A}_{1}\right) / \mathrm{A}_{0}\right] \mathrm{X} 100$

Where $\mathrm{A}_{0}=$ Absorbance of the blank set

$$
\mathrm{A}_{1}=\text { Absorbance of samples and standard }
$$

Phosphomolybdenum assay: For phosphomolybdenum assay $50 \mu \mathrm{l}$ of methanolic extract was incubated in $1 \mathrm{ml}$ of reagent solution $\left(0.6 \mathrm{M} \mathrm{H}_{2} \mathrm{SO}_{4}\right.$, $28 \mathrm{mM}$ sodium phosphate and $4 \mathrm{mM}$ ammonium molybdate). The reaction mixture was agitated on thermal block at $95^{\circ} \mathrm{C}$ for $90 \mathrm{~min}$ and cooled to room temperature. The absorbance of the upper aqueous phase was separated and measured at
$820 \mathrm{~nm}$ against a blank without extract for calculating the reducing activity (15).

Assay of reducing power: The reducing power was estimated (15) by incubating the alcoholic leaf extract in a mixture of $2 \mathrm{ml}$ of $0.2 \mathrm{M}$ phosphate buffer $(\mathrm{pH} 6.6)$ and $2.5 \mathrm{ml}$ of $1 \%$ potassium ferricyanide $(10 \mathrm{mg} / \mathrm{ml})$. The mixture was incubated at $50^{\circ} \mathrm{C}$ for $20 \mathrm{~min}$, cooled and deproteinised with $2.5 \mathrm{ml}$ of $10 \%$ cold trichloroacetic acid (TCA) solution. The supernatant was collected following centrifugation at $8,000 \mathrm{xg}$ for $10 \mathrm{~min}$. Two and a half ml of supernatant was equally diluted by double distilled autoclaved water and allowed to develop color by $0.5 \mathrm{ml}$ of $0.1 \%$ ferric chloride. The absorbance was read at $700 \mathrm{~nm}$.

Total phenolic content: Total phenolics were extracted from ethanolic extract of the sample by centrifugation at $10,000 \mathrm{xg}$ for $15 \mathrm{~min}$ at $4^{\circ} \mathrm{C}$. An aliquot of $0.5 \mathrm{ml}$ supernatantwas reacted with 5 times diluted Folin-Ciocalteu reagent following addition of $20 \%$ sodium carbonate. The mixture was incubated in a boiling water bath for $1 \mathrm{~min}$, cooled and the absorbance was read at $650 \mathrm{~nm}$. Gallic acid was taken as standard to determine total phenolic content (16).

Total flavonoid content: From the ethanolic extract of the sample the supernatant was reextracted with n-butanol-water (1:1) and concentrated under vacuum at $50^{\circ} \mathrm{C}$. The residue was collected and dissolved in 50\% ethanol with consecutive addition of $5 \%$ sodium nitrite and $10 \%$ aluminium nitrite. The reaction was stopped with $1 \mathrm{M}$ sodium hydroxide solution. Using quercetin as standard, the amount of flavonoid was calculated by reading the absorbance at $510 \mathrm{~nm}$ after diluting the supernatant with $30 \%$ ethanol (17).

Total anthocyanin content: The alcoholic leaf extract was diluted with potassium chloride buffer (pH 1.0) and the other with sodium acetate buffer (pH 4.5). On equilibrium for $15 \mathrm{~min}$, the absorbance was read at 510 and $700 \mathrm{~nm}$ against a blank. The content of anthocyanin was measured (18) using the formula:

Anthocyanin $(\mathrm{A})=\left(\mathrm{A}_{510}-\mathrm{A}_{700}\right) \mathrm{pH} 1.0-\left(\mathrm{A}_{510}-\mathrm{A}_{700}\right)$ $\mathrm{pH} 4.5$

Then the monomeric anthocyanin pigment concentration in the original sample was calculated taking cyaniding-3-glucoside as standard using the following formula:

Monomeric anthocyanin pigment $(\mathrm{mg} / \mathrm{l})=(\mathrm{A} X \mathrm{XW}$ X DF X 1000) / ( $\varepsilon$ X 1)

Where MW= Molecular weight (449.2) 
Table 1. Variations in physiological attributes derived through statistical analysis under 2 (a), 4 (b) and 8 (c) days of treatments. The ANOVA was performed at level of significance $p \leq 0.05, p \leq 0.01$ and $p \leq 0.001$

\begin{tabular}{|c|c|c|c|c|}
\hline $\begin{array}{l}\text { Serial } \\
\text { No. }\end{array}$ & Parameters & $\begin{array}{l}\text { T-value } \\
\text { (at } 4 \text { df) }\end{array}$ & F-value & $\begin{array}{c}\text { Critical } \\
\text { Difference (CD) }\end{array}$ \\
\hline 1. & Superoxide $\left(\mathrm{O}_{2 .}{ }^{-}\right)$content & $\begin{array}{l}\text { (a) } 47.01^{* * *} \\
\text { (b) } 11.50^{* * *} \\
\text { (c) } 25.11^{* * *}\end{array}$ & $245.62^{* * *}$ & 0.273 \\
\hline 2. & $\begin{array}{l}\text { Hydrogen peroxide }\left(\mathrm{H}_{2} \mathrm{O}_{2}\right) \\
\text { content }\end{array}$ & $\begin{array}{l}\text { (a) } 19.59^{* * *} \\
\text { (b) } 8.22^{* * *} \\
\text { (c) } 14.40^{* * *}\end{array}$ & $119.45^{* * *}$ & 3.122 \\
\hline 3. & NADP(H) oxidase activity & $\begin{array}{l}\text { (a) } 32.04^{* * *} \\
\text { (b) } 35.50^{* * *} \\
\text { (c) } 54.55^{* * *}\end{array}$ & $1041.95^{* * *}$ & 0.003 \\
\hline 4. & Lipid Peroxidation & $\begin{array}{l}\text { (a) } 0.98 \\
\text { (b) } 7.20^{* * *} \\
\text { (c) } 9.53^{* * *}\end{array}$ & $25.98^{* * *}$ & 0.095 \\
\hline 5. & DPPH scavenging assay & $\begin{array}{l}\text { (a) } 40.26^{* * *} \\
\text { (b) } 63.42^{* * *} \\
\text { (c) } 386.45^{* * *}\end{array}$ & $6032.46^{* * *}$ & 1.734 \\
\hline 6. & ABTS scavenging assay & $\begin{array}{l}\text { (a) } 20.54^{* * *} \\
\text { (b) } 29.66^{* * *} \\
\text { (c) } 45.47^{* * *}\end{array}$ & $1001.19^{* * *}$ & 1.164 \\
\hline 7. & Phosphomolybdenum assay & $\begin{array}{l}\text { (a) } 7.79 * * * \\
\text { (b) } 5.23 * * * \\
\text { (c) } 13.50 * * *\end{array}$ & $43.21^{* * *}$ & 0.005 \\
\hline 8. & Assay of reducing power & $\begin{array}{l}\text { (a) } 9.85^{* * *} \\
\text { (b) } 7.79^{* * *} \\
\text { (c) } 9.18^{* * *}\end{array}$ & $159.57^{* * *}$ & 0.003 \\
\hline 9. & Total phenolics content & $\begin{array}{l}\text { (a) } 2.32 \\
\text { (b) } 4.97^{* * *} \\
\text { (c) } 11.04^{* * *}\end{array}$ & $53.06^{* * *}$ & 0.004 \\
\hline 10. & Total flavonoid content & $\begin{array}{l}\text { (a) } 1.18 \\
\text { (b) } 2.37 \\
\text { (c) } 10.53^{* * *}\end{array}$ & $20.60^{* * *}$ & 0.010 \\
\hline 11. & Total anthocyanin content & $\begin{array}{l}\text { (a) } 1.54 \\
\text { (b) } 2.82^{*} \\
\text { (c) } 5.42^{* * *}\end{array}$ & 0.925 & - \\
\hline 12. & Glutathione activity & $\begin{array}{l}\text { (a) } 15.58^{* * *} \\
\text { (b) } 4.66^{* * *} \\
\text { (c) } 5.41^{* * *}\end{array}$ & $17.87^{* * *}$ & 7.548 \\
\hline 13. & Superoxide dismutase activity & $\begin{array}{l}\text { (a) } 1.96 \\
\text { (b) } 3.93^{*} \\
\text { (c) } 27.55^{* * *}\end{array}$ & 1 & - \\
\hline 14. & Guaiacol peroxidase activity & $\begin{array}{l}\text { (a) } 1.38 \\
\text { (b) } 7.74^{* * *} \\
\text { (c) } 8.50^{* * *}\end{array}$ & $21.78^{* * *}$ & 0.005 \\
\hline 15. & Catalase activity & $\begin{array}{l}\text { (a) } 0.97 \\
\text { (b) } 1.11 \\
\text { (c) } 7.65^{* * *}\end{array}$ & $245.62^{* * *}$ & 0.273 \\
\hline
\end{tabular}

$\mathrm{DF}=$ Dilution factor

$\varepsilon=$ Molar absorptivity (26900)
Glutathione activity: The GSH was analyzed (19) by crushing and extracting the plant material with 50 volumes of buffer containing $15 \mathrm{mM}$ Tris- $\mathrm{Cl}(\mathrm{pH}$ 7.5), $5 \mathrm{mM}$ DTT, $10 \mathrm{mM} \mathrm{MgCl}$, $1 \mathrm{mM}$ EDTA, $1 \mathrm{mM}$ 

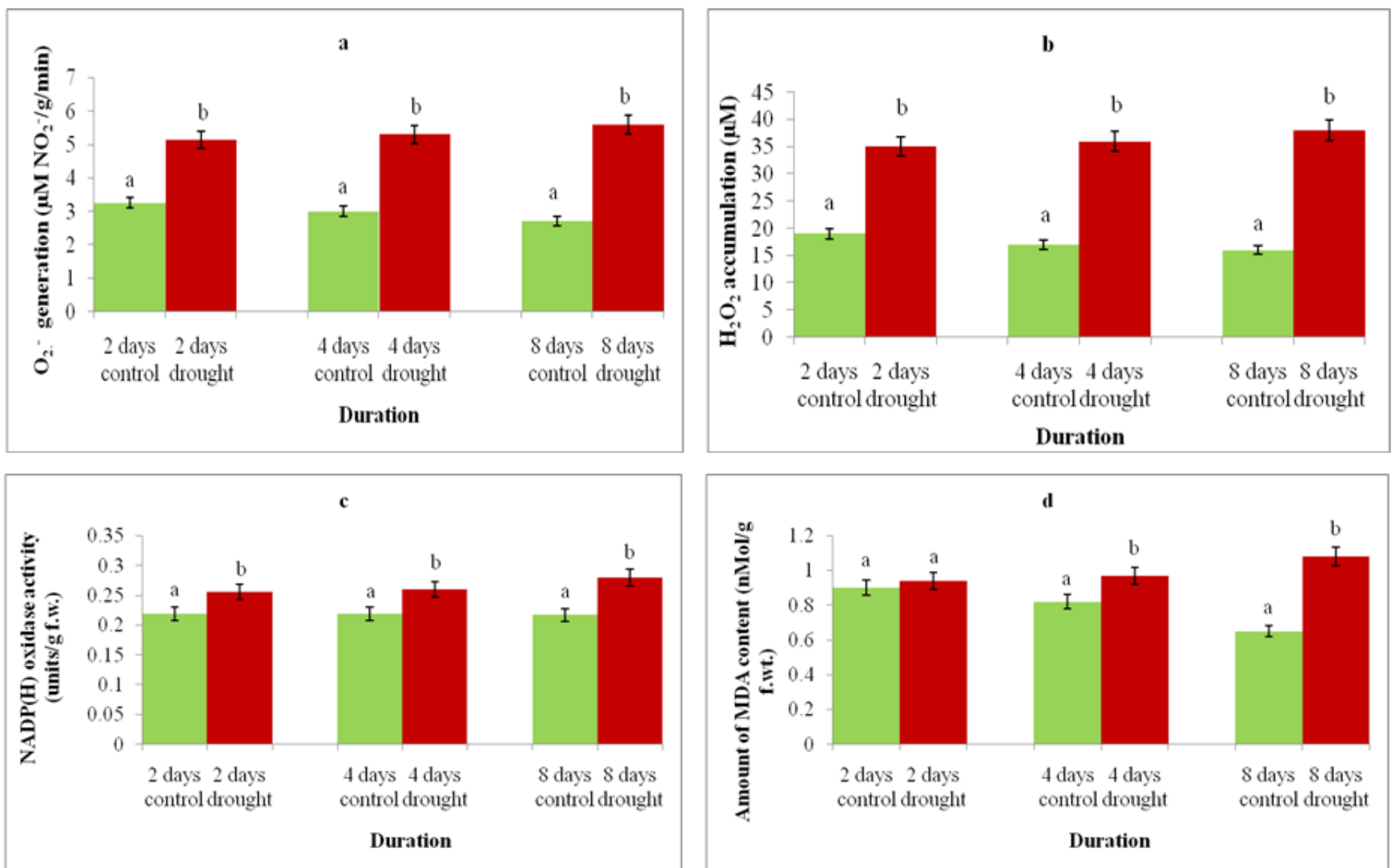

Fig. 1: Changes of $\mathrm{O}_{2}$. generation (a), $\mathrm{H}_{2} \mathrm{O}_{2}$ accumulation (b), $\mathrm{NADP}(\mathrm{H})$ oxidase activity (c) and amount of MDA content (d) of cv. Swarna Sub1 through varying days (2, 4 and 8) under control and water stress. The data presented in bars with \pm SE $(n=3)$ from independent experimental sets at significance level $\mathrm{p} \leq 0.05$ (by student's $t$-test). Different letters on bar represent significant difference.

Mg-acetate and 1\% PVP, followed by centrifugation at $15,000 \mathrm{xg}$ for $20 \mathrm{~min}$ at $4^{\circ} \mathrm{C}$. One $\mathrm{mM}$ PMSF and protease inhibitor cocktail was added to the extraction buffer. The reduced GSH content was derived in a reaction of $1 \mathrm{mM}$ phosphate buffer (pH 7), $2 \mathrm{mM}$ EDTA, $2 \mathrm{mM}$ NADP(H) and $20 \mathrm{mM}$ oxidized glutathione. The absorbance was read at $340 \mathrm{~nm}$ with kinetics for $2 \mathrm{~min}$. The extinction coefficient of NADP(H) $\left(6.22 \mathrm{mM}^{-1} \mathrm{~cm}^{-1}\right)$ was used to calculate the GSH ratio.

Superoxide dismutase activity: From the same enzyme extract SOD (EC 1.15.1.1) was measured with photo reduction of NBT in $100 \mathrm{mM}$ phosphate buffer (pH 7.0), $100 \mathrm{mM}$ EDTA, $10 \mathrm{mM}$ methionine, $10 \mathrm{~mm}$ PMSF, $10 \mathrm{mM} \mathrm{MgCl}$, $10 \mathrm{mM} \beta$-ME, $4 \%$ PVP, $75 \mathrm{mM}$ NBT and 1 to $10 \mu \mathrm{g}$ of enzyme protein. The assay was carried out using 20W fluorescent lamp for $15 \mathrm{~min}$ aganist a non-illuminated sample as blank. The absorbance was read at $560 \mathrm{~nm}$ (20) and SOD activity was expressed as unit / $\mathrm{mg}$ of protein.

Guaiacol peroxidase activity: Activity of GPX (1.11.1.9) was done according to Verma and Dubey (2003) (21). The reaction was carried out with $3 \mathrm{ml}$ of reaction mixture containing $100 \mathrm{mM}$ phosphate buffer (pH 7.5), $10 \mathrm{mM}$ guaiacol, $2 \mathrm{mM} \mathrm{H}_{2} \mathrm{O}_{2}$ and $200 \mu \mathrm{l}$ of enzyme extract. The absorbance was measured at $470 \mathrm{~nm}$ at $30 \mathrm{sec}$ intervals to determine the change in absorbance 0.1 . The enzyme activity was expressed as unit / $\mathrm{g}$ f.wt.

Catalase activity: Catalase (EC 1.11.1.6) was measured in buffer containing $10 \mathrm{mM} \mathrm{H}_{2} \mathrm{O}_{2}, 200$ $\mathrm{mM}$ phosphate buffer (pH 7.0), 2 mM BSA and 10 $\mu \mathrm{g}$ enzyme protein. The fall in OD was recorded at $240 \mathrm{~nm}$ up to $1 \mathrm{~min}$. The activity was recorded according to Verma and Dubey (2003) (21).

Statistical analysis: The data were subjected to analysis of variance coupled with student's $t$-test (SPSS software IBM, USA). Significance of variance was tested at $p \leq 0.05, p \leq 0.01$ and $p \leq 0.001$ levels.

\section{Results}

In response to sub1A QTL under soil-moisture dehydration, plant responded well initially for reactive oxygen species in terms of superoxide $\left(\mathrm{O}_{2}{ }^{-}\right)$and $\mathrm{H}_{2} \mathrm{O}_{2}$. The trend of both the ROS was recorded in a stable manner, however, with no changes through days of tolerance. Still, the variations of $\mathrm{O}_{2}$. content were in the range of 1.58 fold to 2.07 fold (Fig. 1a). On the other hand content of $\mathrm{H}_{2} \mathrm{O}_{2}$ was more upregulated with significant upregulation against control regardless of treatment duration (Fig. 1b). With regard to ROS development pathways the activity of $\mathrm{NADP}(\mathrm{H})$ 

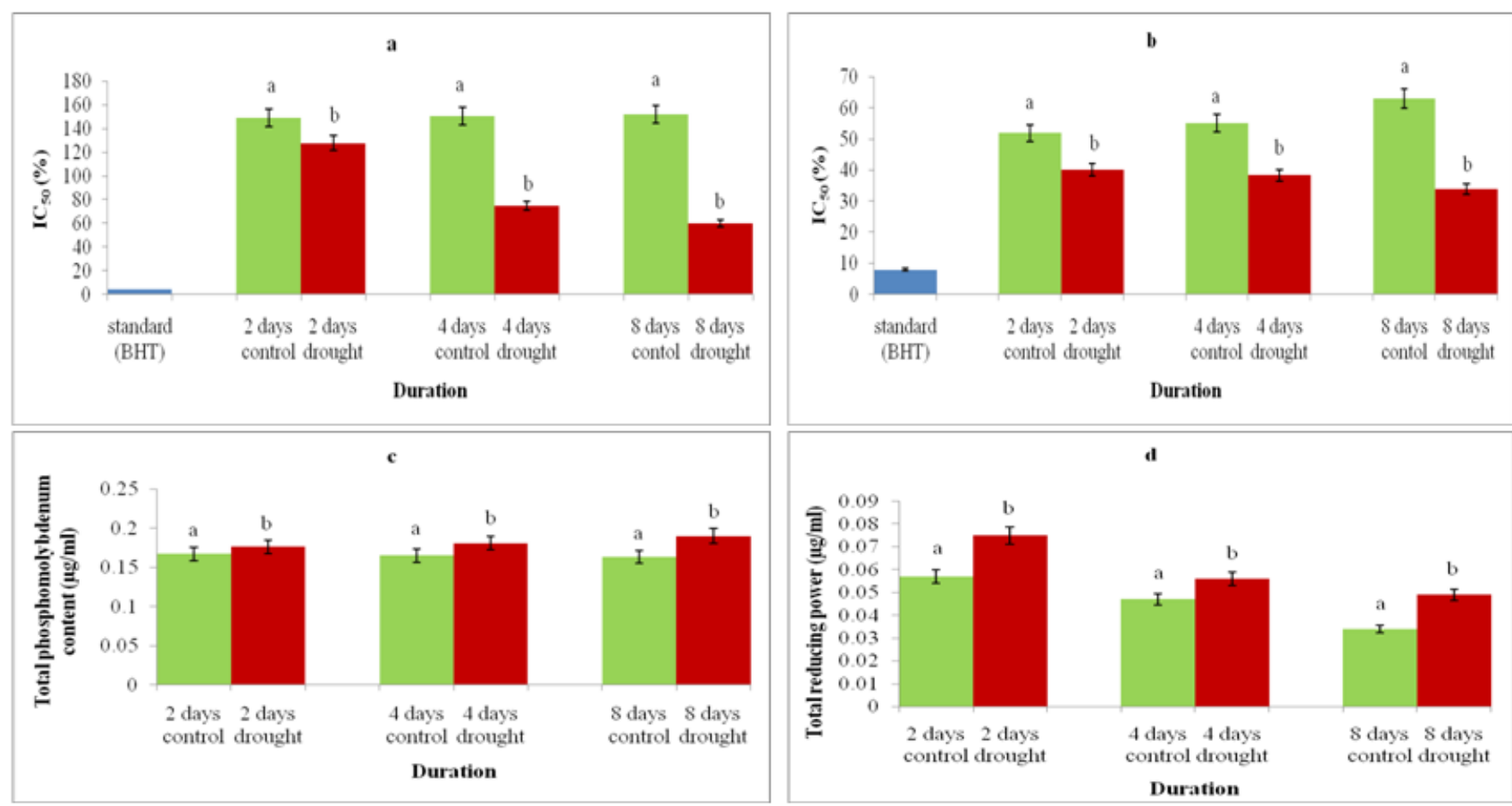

Fig. 2: Changes of DPPH scavenging (a), ABTS scavenging (b), total phosphomolybdenum (c) and total reducing power (d) of cv. Swarna Sub1 through varying days (2, 4 and 8) under control and water stress. The data presented in bars with $\pm S E(n=3)$ from independent experimental sets at significance level $p \leq 0.05$ (by student's $t$-test). Different letters on bar represent significant difference.

oxidase was more concomitant with $\mathrm{O}_{2}$. generation. The activity of $\operatorname{NADP}(\mathrm{H})$ oxidase and $\mathrm{O}_{2}$. were fairly correlated $(\mathrm{r}=1.57)$ regardless of the duration of treatments. The maximum value of oxidase activity as expected was recorded on the $8^{\text {th }}$ day with 1.29 fold increase over control (Fig. 1c). Still, sub1A QTL was less responsive under sufficient soil-moisture condition. It was interesting to note that the plants were in tune with ROS mediated degenerative process under dehydration. It was noted that sub1A QTLs becomes more sensitive to oxidation of lipids induced by dehydration and the increase was in linear order. In comparison to control the maximum production of MDA was recorded on the $8^{\text {th }}$ day with a value that increased by 1.66 fold (Fig. 1d). The MDA content, however, was significant $(p \leq 0.05)$ regardless of days of dehydration.

In another module of antioxidation, plants were evaluated in vitro for their antioxidant potential against simulated ROS generating system. With this view cv. Swarna Sub1 has displayed its efficacy under three successive in vitro ROS inducing systems. A significant fall of antioxidation was observed in the order of 50.59 and $60.84 \%$ on $4^{\text {th }}$ and $8^{\text {th }}$ days of the treatment (Fig. 2a). Still, the activity of antioxidation as derived from $\mathrm{IC}_{50}$ value was significantly $(\mathrm{p} \leq 0.05)$ higher as compared to the standard antioxidant, BHT. The leaf extract was also tested with another scavenging assay where ABTS was used as ROS inducer and BHT the standard. Interestingly as the plant proceeded through days of dehydration, no significant changes were recorded. Still, the antioxidation capacity could not be overcome under dehydration above a critical value in comparison to the control. On consecutive days of dehydration (2, 4 and 8 days) the decline in activities was 22.86, 30.47 and $46.21 \%$ against the control ( $\mathrm{p} \leq 0.05$ ) (Fig. $2 \mathrm{~b}$ ). As expected the $\mathrm{IC}_{50}$ values of sub1A QTL regardless of control and treatment have superseded the standard (BHT) for the same. The phosphomolybdenum assay targets the in vivo antioxidant complexes in the tissue extract and estimates total antioxidant capacity of the plant sample. Thus cv. Swarna Sub1 exhibited a good synthesis capacity of total antioxidants which is evident from the linear increase under days of dehydration against control. The ranges of complex formation were 1.05 to 1.16 fold (Fig. 2c). Finally the plants were evaluated for total non protein thiol content which is equivalent to reducing power of the tissue extract. Though sub1A QTL did not show any significant variation through the treatment durations, however, the reducing power significantly increased over control. The values were in the order of 1.31, 1.19 and 1.44 fold under 2, 4 and 8 days (Fig. 2d). Still, duration was seen to influence the total reducing power through a declining trend regardless of control and dehydration exposure.

The sub1A QTL recorded significant as well as comparable variation in antioxidizing activities in comparison with stable antioxidants, phenolics and its derivatives. The changes in phenolics content were not significant during initial days of dehydration but got significantly upregulated at 4 and 8 days with the values of 1.05 and 1.08 fold increase over control (Fig. 3a). Similarly, the plant 

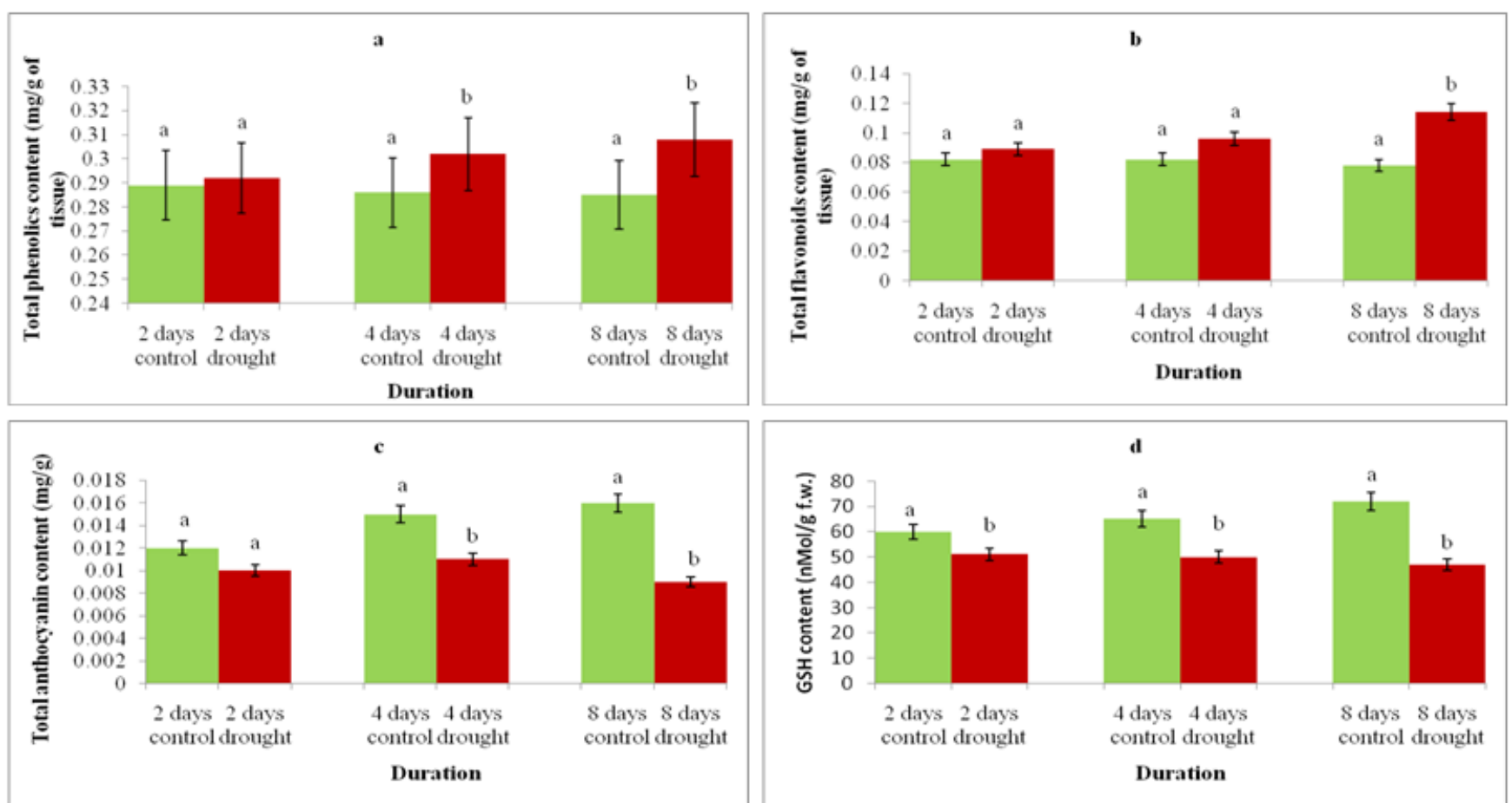

Fig. 3: Changes of total phenolics content (a), total flavanoid content (b), total anthocyanin content (c) and GSH content (d) of cv. Swarna Sub1 through varying days (2, 4 and 8) under control and water stress. The data presented in bars with $\pm \operatorname{SE}(n=3)$ from independent experimental sets at significance level $p \leq 0.05$ (by student's $t$-test). Different letters on bar represent significant difference.

produced high flavonoid content with maximum rise at prolonged duration of stress (8 days) and that recorded 1.46 fold as compared to earlier days (Fig. 3b). Anthocyanin accumulation has been established as linked to sub1A QTL, however similar observation could not obtained in the present study. Interestingly anthocyanin had a proportionate downregulation at each of the stress duration. So, the decline against control were recorded as 16.66, 26.66 and $43.75 \%$ all through the days of exposure (Fig. 3c). The recruitment of reducing potential to maintain a stable redox of the tissue non thiol residues like GSH is very important. Interestingly, sub1A QTLs maintain a homeostasis of the GSH content throughout the experimental period. There recorded hardly any significant ( $p \leq 0.05)$ variation as the plants progressed through the days. Still, the ratio of GSH content under control and dehydration was in the order of 60:51, 65:50 and 72:47 under $2^{\text {nd }}, 4^{\text {th }}$ and $8^{\text {th }}$ day respectively (Fig. $3 d$ ).

Finally the sub1A QTL was evaluated for its antioxidant potential through certain antioxidizing proteins. Inductive responses for dehydration with SOD, GPX and CAT were monitored with their in vitro activities. SOD the first line of defence did not show any significant variation (Fig. 4a). This shows the induction of SOD was rather stable over stress exposure. Almost a similar trend was recorded but with decreasing order in a linear manner for GPX activity through the days of dehydration. On the other hand the maximum fall in activity (60.71\%) was recorded at the 8th day (Fig. 4b). It is more interesting to note that sub1A QTL had comparable trend of lysis as that of $\mathrm{H}_{2} \mathrm{O}_{2}$ by CAT regardless of control and dehydration. The CAT activity was downregulated for each day of dehydration, however, not significant compared to control (Fig. 4c).

\section{Discussion}

The present study establishes the generic behaviour of cv. Swarna Sub1 when it encounters the sequential dehydration on consecutive days and scored its better performances to withstand the cellular dehydration. Undoubtedly in rain-fed or kharif condition, rice cultivars are vulnerable to the sequential appearance of submergence followed by dehydration (vice versa) due to flash flood or/and drought. The semi dwarf low land varieties, which occupy nearly 15 Mha of rice fallows in South East Asia, have to put up with the adverse effects (22). On the other hand cv. Swarna Sub1 is able to continue its sustenance under completely submerged condition for more than 15 days, however, was badly affected on desubmergence. Therefore, transition of oxygen concentration from hypoxic / anoxic to hyperoxic is the key factor for the survival. Similar to cv. Swarna Sub1, few rice genotypes possessing the sub1A like elements are quite sensitive under varying soil moisture condition when exposed to dehydration (23). Therefore, the pattern of cellular responses of cv. Swarna Sub1 under dehydration may be expected to justify the drought tolerance of these genotypes.

Along this line of approach we have initially evaluated the cv. Swarna Sub1 under conditions of elevated redox of induced 

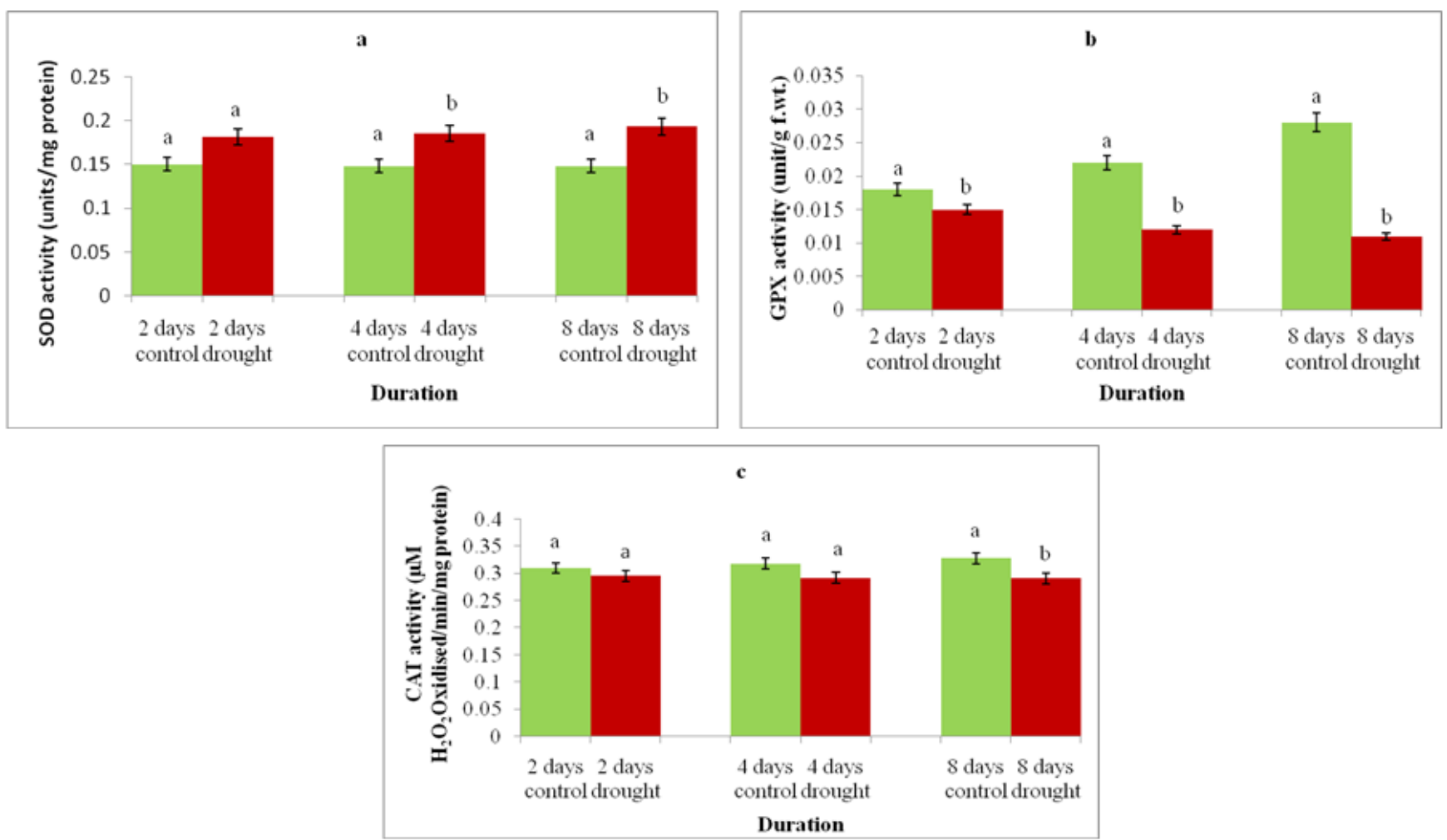

Fig. 4: Changes of SOD activity (a), GPX activity (b) and CAT activity (c) of cv. Swarna Sub1 through varying days (2, 4 and 8) under control and water stress. The data presented in bars with $\pm \mathrm{SE}(\mathrm{n}=3)$ from independent experimental sets at significance level $\mathrm{p} \leq 0.05$ (by student's t-test). Different letters on bar represent significant difference.

dehydration. The gradual increase of both the ROS is quite expected and to counter this effect plants are also tolerant to the default pathways for antioxidation. Reactive oxygen species mostly $\mathrm{O}_{2}$. and its consecutive conversion of $\mathrm{H}_{2} \mathrm{O}_{2}$ may have two impacts: $\mathrm{H}_{2} \mathrm{O}_{2}$ within threshold limit would be a secondary messenger and beyond the level function as free radical or ROS. Rice varieties with varying degrees of $\mathrm{H}_{2} \mathrm{O}_{2}$ accumulation under drought condition have been reported as initial biomarker for cellular antioxidation (24). Still, the chemical conversion of $\mathrm{H}_{2} \mathrm{O}_{2}$ leading to $\mathrm{OH}^{-}$can be attributed to biomolecules like proteins and nucleic acid degeneration. Cultivar Swarna Sub1 has also been reported to stabilize the diffusion of $\mathrm{H}_{2} \mathrm{O}_{2}$ when it is transferred from anoxic to hyperoxic condition upon de-submergence. Therefore, sub1A QTL, more accurately sub1B and sub1C as found in other submergence tolerant line could be scored by $\mathrm{H}_{2} \mathrm{O}_{2}$ accumulation. So, the sub1A possessing landraces may be more vulnerable to dehydration stress. ROS production causes an inhibited metabolism which could be limiting for the plant to realize its growth under drought stress. The over production of free radical is counterbalanced both by non enzymatic and enzymatic antioxidation pathways (25). The cv. Swarna Sub1 in the present experiment has proved quite satisfactory in different profiles of in vitro antioxidation modules. In a series of chemical reactivity this genotype is more efficient in the antioxidation of phosphomolybdenum complex, ABTS and DPPH than in its reducing capacity. Through ongoing changes of drought induction and concomitant free radical / ROS accumulation the potential genotypes could over express some special moieties, like the phenolics, . that have the inherent capacity to donate electrons to ROS and neutralise them. Thus, an assay with total phenolics and one of its major derivative flavonoid was carried out in a similar manner for cv. Swarna Sub1 under conditions of water deficit. The gradual increase of these moieties may alleviate the oxidative stress induced in tissues under dehydration (26). The increase in flavonoids in a compatible manner with in vitro antioxidation parameters would be suggestive of their involvement in neutralising ROS. Flavonoids have an unsaturated nucleus that reduces the ROS by donation of electron (27). Apart from polyphenolics contributing to non enzymatic antioxidant activity, few non thiol moieties are also important. Glutathione, a tripeptide residue with its involvement in reducing redox is a biomarker for oxidative stress (28). During de-submergence exposure to high oxygen tension coupled with irradiance leads to photo oxidative damage. The landraces of rice containing the sub1A locus are more prone to elevate the oxidative redox (29). However, cv. Swarna Sub1 is interesting with its downregulation of GSH. In a reversible cycle of reduced (GSH) to oxidized (GSSG) glutathione, plants are expected to recruit the reducing potential to the bio-molecules. The later is required for stability and native configuration to execute antioxidative responses in enzymatic cascades (30). Therefore, cv. Swarna Sub1 in the 
present case might be expected to exhibit greater reducing power as well as to sustain a reduced potential in tissues under dehydration stress. Contextually anthocyanin activity is quite different in its depletion under dehydration stress as found in the present experiment. Unlike other antioxidants, anthocyanin is a carotenoid derivative with infrequent distribution. Besides, taking part in light harvesting complex system anthocyanin could play a role in quenching the ROS with donation of electron from its nucleophilic residues (31). Submergence with poor diffusion of photosynthetic active radiation might be a bottle neck for light energy acquisition. Therefore, to recruit the efficiency of LHC machineries for more light harnessing the accessory pigment should be over-expressed. However, anthocyanin depletion was the feature under dehydration rather than under submergence. This may be due to its degeneration or/ and non de-novo synthesis of the pigment protein complex. Still, this could be well indexed for cv. Swarna Sub1 sensitivity under dehydration mediated oxidative stress. As a consequence of water stress mediated oxidative damage, cv. Swarna Sub1 has recedes biomolecule degeneration. In a reaction with oxidized peroxylipid radical plants are indexed for their loosening of membrane by lipid hydrolysis. The cv. Swarna Sub1, however, in earlier reports has been claimed to restore it cellular integrity under submergence following de-submergence (32). Still, this QTL might not maintain such a trait under directly induced dehydration. Thus in the present experiment the same QTL behaved in a discriminating manner to realize the oxidative stress and remained more sensitive under dehydration. In other studies for in vitro antioxidation the plant extract has responded well with phosphomolybdenum reduction activity. This simply, however, indirectly implies the amount of antioxidant with its reducing potential in plant extract for a strong antioxidizing agent (phosphomolybdenum as in present case). The conversion of molybdenum with its high oxidation number to lower by electrophilic reactions of the plant extract is another indication for stress tolerance under dehydration (33). In fact, sub1A locus has not been well explored with regard to its antioxidation with quiescence strategies. The tissue hypoxity under submergence and it's tolerance by suppression of normal metabolic groups, may lead to some toxic substance as bioproduct. The latter includes free radicals, with more hydroxyl, per hydroxyl residues. In the present study the activities of molybdenum reduction assay and it's strength strongly becomes evidence antioxidant generation in the tissues. The over-expression of antioxidation activities in vitro both by phosphomolybdenum and reducing power assay are significant concerns in establishing the dehydration vis-a-vis oxidative stress tolerance of Swarna sub 1 . Therefore, a plant species for it's dehydration tolerance develops compatible solutes first and later, the redox nullifying moieties like antioxidants are the preferred screening indices. With this line of thought cv. Swarna Sub1 may be a step ahead of other landraces of rice. Cultivar Swarna Sub1 has also been recommended for its partial tolerance to salinity induced dehydration stress recovery. Still, the present experiment deals with only dehydration mediated oxidative stress and it's recovery as expressed by sub1A QTL (34). With the understanding of plant response through reactive oxygen species lysis or sequester studies the source of it could be relevant to consider. In rice the predominant ROS biosynthetic enzyme, NADP(H) oxidase with it's different activities, molecular variants are reported for sensitivity of oxidative stress (35). In vitro analysis of $\mathrm{NADP}(\mathrm{H})$ oxidase activity in cv. Swarna Sub1 appeared as highly significant to dehydration stress with a marked overexpression against control. Therefore, plants bear a synergistic system of both development of ROS generation and it's consecutive quenching. NADP(H) oxidase activity over the control and all through the days of treatment was also collaborated in a similar manner with antioxidation cascades as evident from in vitro antioxidation components. This refers strongly to sub1A QTL for its sensitivity, in non-degenerative modules under dehydration stress. In turning to stable antioxidants and it's cooperativity with enzymatic antioxidant cv. Swarna Sub1 recorded more variability as it progressed through dehydration stress. Thus, the lysis of $\mathrm{O}_{2}$. to which the plants are more sensitive with SOD activity was significantly higher as compared to control. Therefore, sub1A might have overcome the initial thrust of ROS by a stable performance of SOD activity. Still, plants recorded some more inconstant activities to minimize the effects of $\mathrm{H}_{2} \mathrm{O}_{2} . \mathrm{H}_{2} \mathrm{O}_{2}$ in general is tolerated by plants within cellular threshold and utilises it as inducer for different reactions (36). With the assumption sub1A QTL has an extended range of tolerance to $\mathrm{H}_{2} \mathrm{O}_{2}$ and thereby recorded no increase for $\mathrm{H}_{2} \mathrm{O}_{2}$ lysing cascades. This is evident from a stable, but suppressed activity by both GPX and CAT activity. In the interaction of ethylene mediation for sub1A QTL, in quiescence pathways, $\mathrm{H}_{2} \mathrm{O}_{2}$ is an interfering agent. In rice, the biosynthesis of ethylene and it's transduction over cellular compartments is also hampered by $\mathrm{H}_{2} \mathrm{O}_{2}$ induced oxidation and channel proteins. Cultivar Swarna Sub1 might have moderated the biosynthesis of $\mathrm{H}_{2} \mathrm{O}_{2}$ and no impairment of quiescence mechanism of ethylene is realized (37).

\section{Conclusion}

The present paper is a piece of preliminary documentation where sub1A QTL recorded few 
antioxidation responses under constant dehydration stress. A significant variation in antioxidative cascades through upregulation of both enzymatic and non enzymatic activities was the feature of dehydration responses. In the modules of in vitro antioxidation, plant extract had biomolecules with thepotential to minimize the oxidative damages as well as protection through chelation of ROS. Moreover, as compared to control, the cultivar had the efficiency to minimize the oxidative damages through its enzymatic activities for reduction of ROS. Therefore, sub1A QTL may be expected to follow the same pattern to combat the post submergence mediated oxidative stress as evident from the study.

\section{Conflict of Interest}

The authors have no conflict of interest.

\section{Authors' Contribution}

IS conducted the whole experiment and collected the data. AKD, BS and AG supported the experimental works for different parameters. ND performed statistical analysis. MKA hypothesized the paper concept, designed the experiment, analyzed the data, justified through discussion and written up the whole manuscript.

\section{Acknowledgments}

The experimental work was financially supported by DST-PURSE and DST-INSPIRE programmes. The central instrument facility of University of Kalyani is also acknowledged for partial assistance in chemical analysis.

\section{References}

1. Ismail AM, Singh US, Singh S, Dar MH, Mackill DJ. The contribution of submergence-tolerant (Sub1) rice varieties to food security in flood-prone rainfed lowland areas in Asia. Field Crops Research. 2013 Oct 31;152:83-93. https://doi.org/10.1016/j.fcr.2013.01.007

2. Bona C, de Chiara Moço MC, Mastroberti AA. Cytological aspects during the stretching of collapsed cells in the root aerenchyma of Potamogeton polygonus Cham. \& Schltdl. (Potamogetonaceae). Flora. 2017 Nov 11.

3. Gautam P, Lal B, Tripathi R, Baig MJ, Shahid M, Maharana S, Bihari P, Nayak AK. Impact of Seedling Age and Nitrogen Application on Submergence Tolerance of Sub1 and Non-Sub1 Cultivars of Rice (Oryza sativa L.). Journal of Plant Growth Regulation. 2017:1-4. https://doi.org/10.1007/s00344-016-9661-7

4. Praba ML, Cairns JE, Babu RC, Lafitte HR. Identification of physiological traits underlying cultivar differences in drought tolerance in rice and wheat. Journal of Agronomy and Crop Science. 2009 Feb 1;195(1):30-46. https://doi.org/10.1111/j.1439-037X.2008.00341.X

5. Sarkar B, De AK, Adak MK. Physiological characterization of SUB1 trait in rice under subsequent submergence and re-aeration with interaction of chemical elicitors. Plant Science Today. 2017 Nov 27;4(4):177-90 https://doi.org/10.14719/pst.2017.4.4.351

6. Ismail AM, Singh US, Singh S, Dar MH, Mackill DJ. The contribution of submergence-tolerant (Sub1) rice varieties to food security in flood-prone rainfed lowland areas in Asia. Field Crops Research. 2013 ;152:83-93. https://doi.org/10.1016/j.fcr.2013.01.007

7. Murashige T, Skoog F. A revised medium for rapid growth and bio assays with tobacco tissue cultures. Physiologia plantarum. 1962 Jul 1;15(3):473-97. https:// doi.org/10.1111/j.1399-3054.1962.tb08052.x

8. Elstner EF, Heupel A. Inhibition of nitrite formation from hydroxylammoniumchloride: a simple assay for superoxide dismutase. Analytical biochemistry. 1976 Feb 1;70(2):616-20. https://doi.org/10.1016/00032697(76)90488-7

9. Ghosh N, Adak MK, Ghosh PD, Gupta S, Gupta DS, Mandal C. Differential responses of two rice varieties to salt stress. Plant Biotechnology Reports. 2011 Jan 1;5(1):89-103. $\quad$ https://doi.org/10.1007/s11816-0100163-y

10. Ishida A, Ookubo K, Ono K. Formation of hydrogen peroxide by NAD (P) $\mathrm{H}$ oxidation with isolated cell wall-associated peroxidase from cultured liverwort cells, Marchantia polymorpha L. Plant and cell physiology. 1987 Jun 1;28(4):723-6.

11. Heath RL, Packer L. Photoperoxidation in isolated chloroplasts: I. Kinetics and stoichiometry of fatty acid peroxidation. Archives of biochemistry and biophysics. 1968 Apr 1;125(1):189-98. https://doi.org/ $\underline{10.1016 / 0003-9861(68) 90654-1}$

12. Dey P, Chaudhuri D, Chaudhuri TK, Mandal N. Comparative assessment of the antioxidant activity and free radical scavenging potential of different parts of Nerium indicum. International Journal of Phytomedicine. 2012 Jan 1;4(1):54.

13. Re R, Pellegrini N, Proteggente A, Pannala A, Yang M, Rice-Evans C. Antioxidant activity applying an improved ABTS radical cation decolorization assay. Free radical biology and medicine. 1999 May 1;26(910):1231-7. $\underline{\text { 5849(98)00315-3 }}$

https://doi.org/10.1016/S0891-

14. Almulaiky YQ, Alshawafi WM, Al-Talhi HA, Zeyadi M, Anwar F, Al-abbasi FA, Khan R, Kumar V. Evaluation of the Antioxidant Potential and Antioxidant Enzymes of Some Yemeni Grape Cultivars. Free Radicals \& Antioxidants. 2017 Jan 1;7(1).

15. Ferreira IC, Baptista P, Vilas-Boas M, Barros L. Freeradical scavenging capacity and reducing power of wild edible mushrooms from northeast Portugal: Individual cap and stipe activity. Food chemistry. 2007 Jan 1;100(4):1511-6. https://doi.org/10.1016/j.foodchem.2005.11.043

16. Mohsen SM, Ammar AS. Total phenolic contents and antioxidant activity of corn tassel extracts. Food chemistry. $\quad 2009 \quad$ Feb $1 ; 112(3): 595-8$. https://doi.org/10.1016/j.foodchem.2008.06.014

17. Basu S, Roychoudhury A, Saha PP, Sengupta DN. Differential antioxidative responses of indica rice cultivars to drought stress. Plant Growth Regulation. 2010 Jan 1;60(1):51. https://doi.org/10.1007/s10725009-9418-4 
18. Giusti MM, Wrolstad RE. Characterization and measurement of anthocyanins by UV-visible spectroscopy. Current protocols in food analytical chemistry. $2001 \mathrm{Aug}$.

19. Li F, Wang J, Ma C, Zhao Y, Wang Y, Hasi A, Qi Z. Glutamate receptor-like channel3. 3 is involved in mediating glutathione-triggered cytosolic calcium transients, transcriptional changes, and innate immunity responses in Arabidopsis. Plant physiology. 2013 Jul 1;162(3):1497-509. https://doi.org/10.1104/pp.113.217208

20. Cakmak I, Marschner H. Magnesium deficiency and high light intensity enhance activities of superoxide dismutase, ascorbate peroxidase, and glutathione reductase in bean leaves. Plant physiology. $1992 \mathrm{Apr}$ 1;98(4):1222-7. https://doi.org/10.1104/pp.98.4.1222

21. Verma S, Dubey RS. Lead toxicity induces lipid peroxidation and alters the activities of antioxidant enzymes in growing rice plants. Plant Science. 2003 Apr 30;164(4):645-55. https://doi.org/10.1016/S0168$\underline{\text { 9452(03)00022-0 }}$

22. Olk DC, Cassman KG, Randall EW, Kinchesh P, Sanger LJ, Anderson JM. Changes in chemical properties of organic matter with intensified rice cropping in tropical lowland soil. European Journal of Soil Science. $\quad 1996 \quad$ Sep 1;47(3):293-303 https://doi.org/10.1111/j.1365-2389.1996.tb01403.x

23. Banerjee S, Ghosh N, Mandal C, Dey N, Adak MK. Physiological basis of submergence tolerance in rice genotypes with reference to carbohydrate metabolism. Plant Gene and Trait. 2015 Apr 30;6.

24. Banerjee S, Dey N, Adak MK. Assessment of some biomarkers under submergence stress in some rice cultivars varying in responses. American Journal of Plant Sciences. 2015 Jan 6;6(01):84. https://doi.org/10.4236/ajps.2015.61010

25. Cruz de Carvalho MH. Drought stress and reactive oxygen species: production, scavenging and signaling. Plant Signaling \& Behavior. 2008 Mar 1;3(3):156-65. https://doi.org/10.4161/psb.3.3.5536

26. Du H, Wang $\mathrm{N}$, Cui F, Li X, Xiao J, Xiong L. Characterization of the $\beta$-carotene hydroxylase gene DSM2 conferring drought and oxidative stress resistance by increasing xanthophylls and abscisic acid synthesis in rice. Plant Physiology 2010;154(3):1304-18.

https://doi.org/10.1104/pp.110.163741

27. Leopoldini M, Rondinelli F, Russo N, Toscano $M$. Pyranoanthocyanins: a theoretical investigation on their antioxidant activity. Journal of agricultural and food chemistry. 2010 Jul 13;58(15):8862-71. https://doi.org/10.1021/jf101693k

28. Soga T, Baran R, Suematsu M, Ueno Y, Ikeda S, Sakurakawa T, Kakazu Y, Ishikawa T, Robert M, Nishioka T, Tomita M. Differential metabolomics reveals ophthalmic acid as an oxidative stress biomarker indicating hepatic glutathione consumption. Journal of Biological Chemistry. 2006 Jun 16;281(24):16768-76. https://doi.org/10.1074/jbc.M601876200
29. Arbona V, Manzi M, Zandalinas SI, Vives-Peris V, Pérez-Clemente RM, Gómez-Cadenas A. Physiological, metabolic, and molecular responses of plants to abiotic stress. InStress Signaling in Plants: Genomics and Proteomics Perspective, Volume 2 2017 (pp. 1-35). Springer, Cham.

30. Ghosh N, Das SP, Mandal C, Gupta S, Das K, Dey N, Adak MK. Variations of antioxidative responses in two rice cultivars with polyamine treatment under salinity stress. Physiology and Molecular Biology of Plants. $\quad 2012 \quad$ Oct 1;18(4):301-13 https://doi.org/10.1007/s12298-012-0124-8

31. Lopez-Martinez LX, Oliart-Ros RM, Valerio-Alfaro G, Lee $\mathrm{CH}$, Parkin KL, Garcia HS. Antioxidant activity, phenolic compounds and anthocyanins content of eighteen strains of Mexican maize. LWT-Food Science and Technology. 2009 Jul 31;42(6):1187-92. https://doi.org/10.1016/j.lwt.2008.10.010

32. Sarkar RK, Bhattacharjee B. Rice genotypes with SUB1 QTL differ in submergence tolerance, elongation ability during submergence and re-generation growth at re-emergence. Rice. 2011 Dec 1;5(1):7. https://doi.org/10.1007/s12284-011-9065-Z

33. Lu Y, Li Y, Zhang J, Xiao Y, Yue Y, Duan L, Zhang M, Li Z. Overexpression of Arabidopsis molybdenum cofactor sulfurase gene confers drought tolerance in maize (Zea mays L.). PLoS One. 2013 Jan 10;8(1):e52126. https://doi.org/10.1371/journal.pone.0052126

34. Schmitz AJ, Folsom JJ, Jikamaru Y, Ronald P, Walia H. SUB1A-mediated submergence tolerance response in rice involves differential regulation of the brassinosteroid pathway. New Phytologist. 2013 Jun 1;198(4):1060-70. https://doi.org/10.1111/nph.12202

35. Noctor G, Mhamdi A, Foyer $\mathrm{CH}$. Oxidative stress and antioxidative systems: recipes for successful data collection and interpretation. Plant, cell \& environment. $2016 \quad$ May 1;39(5):1140-60. https://doi.org/10.1111/pce.12726

36. Nahar K, Hasanuzzaman M, Ahamed KU, Hakeem KR, Ozturk M, Fujita M. Plant responses and tolerance to high temperature stress: Role of exogenous phytoprotectants. InCrop production and global environmental issues 2015 (pp. 385-435). Springer, Cham.

37. Sarkar RK, Ray A. Submergence-tolerant rice withstands complete submergence even in saline water: Probing through chlorophyll a fluorescence induction OJIP transients. Photosynthetica 2016 Jun 1;54(2):275-87. $\quad$ https://doi.org/10.1007/s11099-016$\underline{0082-4}$ 